\title{
MONTALVO, LA REFLEXIÓN ÉTICA Y LA PRODUCCIÓN INTELECTUAL
}

Marcelo H. Andocilla L.

UNIVERSIDAD CENTRAL DEL ECUADOR marandocilla@hotmail.com

Recibido: 22 - junio - 2016 / Aprobado: 20 - agosto - 2016

\section{Resumen}

Juan Montalvo sigue despertando el interés de las generaciones pasadas y presentes; es uno de los autores ecuatorianos de mayor repercusión en América Latina. La presente exposición es un ensayo que intenta acercarse a la obra montalvina desde una zona cercana a la filosofía: la ética; y, de esta, la formación del carácter ético que demostró Montalvo en su obra y vida, así como las interrelaciones que él estableció en su polémica sobre la creación literaria que bien podría extenderse a la creación científica y la publicación de sus resultados.

Palabras clave: Juan Montalvo, carácter ético, creación literaria.

\begin{abstract}
Juan Montalvo continues awakening the interest of past and present generations; it's one of the most influential Ecuadorian authors in Latin America. The present essay tries to approach the montalvina work from an area close to the philosophy: the ethics; and from this, the formation of the ethical character that Montalvo demonstrated in his work and life, as well as the interrelations he established in his controversy over literary creation that could well extend to scientific creation and publication of its results.
\end{abstract}

Keywords: Juan Montalvo, ethical character, literary creation. 


\section{El carácter ético en Montalvo}

La talla intelectual de Montalvo se eleva por múltiples aristas de la capacidad y racionalidad humana. Sin embargo, nuestro ilustre coterráneo, dicen, no fue un filósofo aun cuando sus juicios se configuran como premisas de verdaderos sistemas filosóficos. Para Gonzalo Zaldumbide:

(Montalvo)... asumió el oficio de pensador, y lo encumbró en el sentido de hombre que contempla y habla, poniendo en el tono, en el acento de sus escritos más que en sus razones, el ascendiente de la persuasión, jamás hizo Montalvo hincapié en doctrinas más o menos sistematizadas (Zaldumbide, 1938, p. 24).

Esta afirmación no quiere decir que su pensamiento sea ausente de una riqueza filosófica ganada en las lecturas de los pensadores de la Grecia antigua y de europeos contemporáneos, especialmente los ilustrados como Montesquieu, Voltaire, Rousseau. Benjamín Carrión confirma que Montalvo "no nos dejó una ordenación de conceptos, una teoría, un sistema. Tampoco ha ahondado en el estudio y la comprensión de la filosofía, ni se ha afiliado a ninguna línea orgánica de interpretación del mundo, la vida, el hombre..." (Carrión, 1961, pp. 25-26).

La ética, en cuanto estructura sistemática, emerge de los preceptos de la filosofía y se configura con ella como un saber organizado, los estudios de la práctica moral de los seres humanos. Tan ligada a la filosofía que los orígenes sistemáticos sobre el bien y el mal se encuentran en la antigua Grecia, admirada por Montalvo. A partir de Grecia, a dos milenios de filosofía, la ética se ha planteado y vuelto a plantear las mismas preguntas sobre el bien y el mal.

En dos mil cuatrocientos años el concepto de ética ha venido variando: desde el eethos así, escrito con doble vocal ee, y que se le encuentra en los textos homéricos de la Ilíada y la Odisea, fue descrito como "guarida", donde el animal se pone a salvo, su morada, su hábitat, razón por la cual cambió luego a ethos, con una vocal simple relacionado como costumbre, hábito y que ascendió a la significación de carácter (Pérez Tamayo Ruy, 2014, pp. 13-15). De hábitat a hábito y carácter que es luego el concepto utilizado por Aristóteles.

Y claro, el carácter es el desarrollo del hábito, de la costumbre. El carácter se adquiere por medio del hábito. Y aquí una aclaración y diferenciación: el carácter moral, se adquiere, casi como un contagio, por la costumbre; pero, el carácter ético se conquista por medio de la costumbre. Adquirir y conquistar. Y es que nacemos en una sociedad con una moral que no la elegimos, pero la repetimos, con valores que otros los eligieron, y así unos fueron tomando de otros y vamos como haciéndonos parte del montón. Mientras que el ethos debe ser, tiene que ser y es libre; y este "tiene" es una demanda a ser conquistado, de manera consciente, racional; reflexiva, autónoma, libre. En libertad, dejar de moldearse por costumbres que han de seguir sin cuestionarse: costumbre que estableció una mayoría, o una minoría, y que así se esparció, como por contagio. 
Desde Platón, pasando por Aristóteles y Heidegger, la ética nos plantea al menos dos significados: 1) como un estudio racional de los fenómenos morales, 2) como una calificación de un acto humano con deliberación previa y por tanto con capacidad de elección. Razón, deliberación y elección en libertad. Funciones del cerebro superior. Más allá de los sentimientos y las emociones, la ética nos salva así, de ser uno más del montón. Nos salva de la moral consensuada y sin crítica. Dice en el episodio del Cura de santa gracia, en los Siete tratados:

Libertad de pensar, de formar conceptos, opiniones y este santo derecho es mortal para la fe (...) la libertad de raciocinio va derechamente a la libertad de conciencia: ésta es prohibida por vuestro soberano y así no podéis quererla sin caer en rebelión y apostasía o sois juguetes miserables de la ignorancia que no da con el toque de las dificultades (Montalvo, Siete tratados, 2008, p. 218).

Resulta que, por esta razón, Sócrates rompió con la moral de la época, tanto que fue condenado a muerte por "inmoral"; con su muerte dejó la enseñanza que es peor cometer el mal que recibirlo, dañar que ser dañado. El genio y la pluma de Montalvo describe: "Pitágoras muere en el fuego, Sócrates apura la cicuta; Platón es vendido como esclavo; Jordán Bruno, Savonarola son pasto del verdugo. ¿Quién más? Todos piensan que el matador de César dijo una gran cosa cuando exclamó: "Oh virtud, eres sentencia de muerte"; y Montalvo, él mismo, fue declarado hereje, clerófobo, condenado a vivir en la persecución y morir en el destierro con su indignación fulminante, su coraje casi heroico. Si ponemos atención, todos los nombrados en el párrafo anterior en El cosmopolita (Montalvo, El cosmopolita, 2007, p. 563) se opusieron a los moralmente "buenos" y "justos", que seguían las normas establecidas, funcionales, domesticadoras, pero carentes de ética. Fue ese carácter ético, que nos impulsa a salvarnos del mal, lo que en los hechos constituyó la personalidad de Montalvo, más allá de las aparentes limitaciones en la sistematización y adhesión a alguna de las escuelas del pensamiento y la filosofía.

Montalvo, lo reconoce Agustín Cueva en la crítica de la obra de él, fue un hombre que tuvo el coraje - poco común en el siglo XIX- "de mandar al diablo a un obispo, a algunos tiranuelos y a unos cuantos nobles de opereta" (Cueva, Entre la Ira y la Esperanza, 1967, p. 150). Lo cierto es que el carácter y personalidad, en sus escritos, se levantaron erigiéndose sobre aquellos valores superficiales y moralistas que representó esta clase de "nobletes", sus gobiernos y el clero. Y aunque no apunta al sistema, Montalvo lo hizo a sus comunes sostenedores de la época; época particular, configurada por la estructura feudal, sus derivaciones y contradicciones de opulencia y miseria (Cueva, Lecturas y rupturas, 1986, pp. 38-43) en la que la aristocracia y la Iglesia disponían del poder, económico e ideológico.

Por otra parte, don Juan Montalvo "amaba a don Quijote -dice uno de sus biógrafos, Galo René Pérez- por el ímpetu irresistible con que el nervioso caballero relampagueaba de cóleras súbitas y justicieras" (Pérez, 2003, p. 86), Así configuró, en su carácter, el ejercicio de la beligerancia que a decir de Unamuno se expresó en 
sus insultos... Pero el mismo Montalvo en El espectador, uno de sus últimos libros, puntualiza y aclara "con los perversos yo he sido implacable; mas pregúntenme si he quitado la vida a un pajarito, si he pisado adrede sobre una hormiga" (Pérez, 2003, p. 87). Y en su obra se expresa, en varias páginas, esta dualidad contradictora pero unitaria, de durezas, desafíos, orgullo, con los de conmiseraciones, delicadezas y congojas.

Para inicios del siglo XX y a partir de Max Scheler ${ }^{1}$ se va configurando una ética de la relación con el otro y con lo otro, con base en un mundo de valores, que retan a ser descubiertos en las esferas de la realización humana; pero Montalvo ya lo intuyó antes que Scheler y Hartaman: "La virtud de las cosas está en ellas mismas, no en la opinión de los que juzgan de ellas, las buenas prevalecen, las sublimes quedan inmortales" (Montalvo, Siete tratados, 2008, p. 582). El valor está en las cosas, es una cualidad de ellas y así los bienes no son sino cosas portadoras de valores y todo su libro de Los siete tratados dedica a esos valores: la nobleza, la belleza, el genio, los héroes...

"El privilegio de la virtud -dice en El cosmopolita- es el respeto aun de sus enemigos; la virtud hecha de sí un ambiente que deleita aun a los malos" (Carrión, 1961, p. 22). "Equidad, probidad, generosidad, largueza, honra, valor son granos de oro que descienden por entre las sandeces del gran loco, y van a crecer el caudal de las virtudes", exalta en "El buscapié", al hablar sobre el Don Quijote (Montalvo, Siete tratados, 2008, p. 580).

Y en Jara, alertando a nuestras conciencias, aborda como un contravalor al odio, cuando en boca de Eudoxia dice subrayando "La venganza a su modo de ver: es una religión. Perdonar un agravio es cobardía; olvidar una ofensa, infamia: la nobleza consiste en vengarse; un hombre no puede vivir si no mata a su ofensor"; pero, cuando hace hablar al vicario reflexiona él mismo, y en él, Montalvo: "no hay bestia más fiera que el hombre cuando la cólera le oscurece el juicio" (Sacoto, 1973, p. 287).

Aborda él, no consejos morales; sí, reflexiones sobre determinados valores. Estas reflexiones lo convierten en un eticista sin él proponérselo y sin querer reducir su obra. Los biógrafos de Montalvo coinciden que en sus libros se percibe un "elogio a las virtudes y condenación de los vicios" dice Antonio Sacoto en su libro Juan Montalvo, el escritor y el estilista. En realidad va confrontando valores y contravalores como sucede en su Geometría moral donde describe al sí como "una línea recta" y al no como "curva llena de quiebros, línea por la cual no podemos salir a ninguna parte", dice, y la asocia con todo lo oscuro y cerrado. "La ignorancia es un no rústico; la avaricia, un no sórdido vestido de andrajos. El hambre misma es negación desesperada; y la muerte un no espantoso que ciega y aturde al mundo con su oscuridad

1 Max Sheler(1874-1928), establece las bases de una ética del valor luego de criticar la ética formalista de Kant. En la teoría de los valores, como una cualidad de las cosas, se establece que éstos tienen polaridad y jerarquía: a lo bueno se opone lo malo, a lo bello lo feo; pero a la vez la elegancia es inferior a la belleza y ésta a la bondad (Marías, 1940). 
y su silencio” (Montalvo, Geometría Moral, 1998, p. 7). Y en su combate a Ignacio de Veintimilla, en Las catilinarias (Montalvo, Las catilinarias, 1998, p. 42) resuena:

Ignacio de Veintimilla no se contenta con la bolsa; le quita la camisa a la República, la deja en cueros, y allá se lo haya con su desnudez la pobre tonta: ¿por qué no se defiende? El que se deja robar, pudiendo tomarse a brazos y dar en tierra con el salteador, es vil que no tiene derecho a la queja.

Así va, Montalvo, perfilando este carácter. Carácter, disposición del espíritu para acometer acciones. Regio carácter que le acompañó hasta la muerte dando una lección de entereza moral; como Héctor, el mejor guerrero de Troya, que espera a Aquiles el campeón de los aqueos, de pie y con firmeza en las afueras de la ciudad, aun a sabiendas que es más fuerte que él y probablemente va a morir; lo hace en defensa de sus conciudadanos. Montalvo viste de etiqueta y encarga unas flores: "El paso a la eternidad es el paso más serio del hombre”.

\section{La ética en la producción intelectual}

En el prólogo del "Buscapié" o el "Ensayo de una imitación de un libro inimitable" (Montalvo, Capítulos que se le olvidaron a Cervantes, 2005, pp. 23-40) aborda tres categorías tan importantes en la vida, particularmente en la producción intelectual y en nuestro caso, la docencia: la competencia, la rivalidad y la emulación.

La rivalidad nunca es inocente, cómplice del odio, trae en su seno la envidia (...) No rivalizamos con alguien sino porque tenemos entendido que nos disputa nuestro bien y menoscaba nuestra dicha, juzgándole así tan adverso a nuestros fines (...) Donde cabe la rivalidad no hay lugar para la virtud, de ella proceden mil desgracias y aún pueden nacer delitos.

Y luego sigue para destacar y aclarar que la rivalidad no equivale a la competencia, aunque de ésta reconoce dos expresiones, como virtud y como vicio:

Dos personas que se juzgan dotadas de prendas, medios, facultades iguales, pueden entrar en competencia, esta es muchas veces noble esfuerzo, que ejercitándose sin perjuicio de nadie, nos guía al mejoramiento de nosotros mismo. No podemos rivalizar con uno sin aborrecerle; competimos con otro al paso que le admiramos, pues justamente nuestro ahínco se cifra en igualarle o superarle en cosa buena o grande. El prurito de la competencia se halla puesto entre las virtudes y los vicios, propende por la mayor parte de las primeras; cuando se recuesta a los segundos, bastardea, y viene a ser defecto (sic).

\section{Pero, nos dice a continuación:}

La emulación no corre este peligro, emulación es siempre ahínco por imitar los hechos de un hombre superior, éste sirve de modelo al que emula sus acciones, y 
tanto el uno como el otro han de experimentar dentro de sí el sublime impulso que mueve a las cosas grandes.

Hay que impulsar la emulación, como un sí según Montalvo; como un valor. Es en la emulación precisamente donde Montalvo halla la inspiración de su libro Capitulos que se le olvidaron a Cervantes, en cuyo prólogo defiende la grandeza de su "imitación de lo inimitable"

...mas, entre el crear y el imitar, entre el tener y el coger, entre el producir y el pedir, la palma se le llevará siempre el ingenio rico y fecundo que halla cosas nuevas, o reviste las conocidas de tal modo que vienen a parecer originales y sorprendentes.

La imaginación no es más que la memoria en forma de otra facultad lo subraya él mismo, como rememorando a Percy Shelley, ${ }^{2}$ quien concuerda que toda creación no es más que la imaginación de lo que existe. Aclara, sin embargo, que "escritores hay tan sin género de aprensión, que ni siquiera se toman la molestia de dar forma a las alhajas que saltean" proclamando, al inicio del capítulo XI que: "Entre los pecados y vicios de las buenas letras, el peor a los ojos de los humanistas hombres de bien, es sin duda el que llamamos plagio o robo de pensamientos y discursos", dando a la creación literaria -y desde luego a la científica, lo añado yo extensivamente- la analogía de un precioso collar

de piedras preciosas de diferentes colores artísticamente engarzados, representará a la memoria: el diamante cristalino, el rubí que está echando fuego, el zafiro de celestes visos, la verde esmeralda, el ónice apagado, todos con sus significaciones respectivas, darán idea de la memoria, esta rica facultad que si se desquicia un punto, cae desbaratada (...) sin almáciga de ideas, no hay facultad imaginativa (Montalvo, Siete tratados, 2008, pp. 90-91).

Dice así, con esa brillantez. Una lección pedagógica y ética sobre la creación intelectual, la creación sobre lo creado; distinto del plagio, de quienes obligados a escribir, en las demandas de esta sociedad que todo lo transforma en mercancía, predominando la cantidad sobre la calidad, en medio de un filisteísmo sin alma, no recurren sino al robo de las piedras preciosas del intelecto.

Es el análisis montalvino de orientar la conducta acorde con las facultades superiores del espíritu al que lo define como conciencia y no solo de conformidad con los instintos o incluso de la inteligencia como razón instrumental (Paladines, 1988, p. 28). “... por la razón juzgamos, por ella tenemos conocimientos de lo pasado, por ella prevemos el porvenir” (Montalvo, El cosmopolita, tomo I, 2007, p. 341).

2 Poeta y ensayista de origen Inglés (1792-1822), catalogado como poeta romántico, influenciado por la Ilustración, pregonó el pensamiento liberal y murió en el destierro en Italia. Entre otros, como William Blake, generaron una "tendencia creadora" y una "fantasía representativa" como imaginación y adelanto del futuro. Montalvo nace 10 años luego de la muerte de Sheley (1832), es muy posible que haya conocido parte de su obra. 
Pongamos atención cuando escribe sobre Cervantes y su trascendencia, que le define en la inspiración Socrática que "solo por medio de la virtud podemos componer obras maestras", y exclama:

Escritor cuyo fin no sea de provecho para sus semejantes, les hará un bien con tirar su pluma al fuego, provecho moral, universal; no el que proclaman los seudo-sabios que adoran al dios Egoísmo y le casan a hurto con la diosa Utilidad en el ara de la impudicia (Montalvo, Capitulos que se le olvidaron a Cervantes, 2005, p. XI).

\section{Bibliografía}

Carrión, B. (1961). El pensamiento vivo de Montalvo. Buenos Aires: Lozada.

Cueva, A. (1967). Entre la ira y la esperanza. Quito, Ecuador: Planeta del Ecuador.

Cueva, A. (1986). Lecturas y rupturas. Quito, Ecuador: Planeta del Ecuador.

Marías, J. (1940). Historia de la filosofía. Barcelona, España: Alianza.

Montalvo, J. (2005). Capitulos que se le olvidaron a Cervantes. Ambato, Ecuador: Casa de la Cultura Ecuatoriana.

Montalvo, J. (2007). El cosmopolita, tomo I. Ambato, Ecuador: Casa de Montalvo.

Montalvo, J. (2007). El cosmopolita. Ambato, Ecuador: Casa de Montalvo.

Montalvo, J. (1998). Geometría moral. Ambato, Ecuador: Casa de Montalvo.

Montalvo, J. (1998). Las catilinarias. Ambato, Ecuador: Municipalidad de la Ciudad de Ambato.

Montalvo, J. (2008). Siete tratados. Ambato, Ecuador: Casa de Montalvo.

Paladines, C. (1988). Aporte de Juan Montalvo al pensamiento liberal. Quito, Ecuador: Fundación Friedrich-Naumann.

Pérez, G.R. (2003). Vida de Juan Montalvo. Quito, Ecuador: Casa de la Cultura Ecuatoriana.

Pérez Tamayo Ruy (2014). La construcción de la bioética. México D.F, México: Fondo de Cultura Económica.

Sacoto, A. (1973). Juan Montalvo el escritor y el estilista. Quito, Ecuador: Casa de la Cultura Ecuatoriana.

Zaldumbide, G. (1938). Montalvo y Rodó. New York: Instituto de las Españas. 